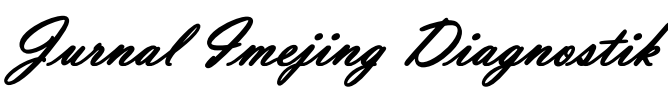

e-ISSN 2621-7457, p-ISSN 2356-301X

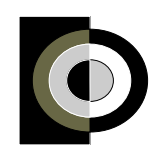

http://ejournal.poltekkessmg.ac.id/ojs/index.php/jimed/index

\title{
Analisis Noise pada Radiografi Thorax Pulmonum pada Penerapan Modifikasi Faktor Eksposi Aturan 10 kV
}

\author{
Luthfi Rusyadi ${ }^{1}$, Siti Daryati ${ }^{2}$, Dwi Rochmayanti ${ }^{3}$, Andrey Nino Kurniawan ${ }^{4}$ \\ ${ }^{1,2,3,4)}$ Poltekkes Kemenkes Semarang, Indonesia \\ Corresponding Author: Luthfi Rusyadi \\ e-mail: luthfirusyadi77@gmail.com
}

Received: January $29^{\text {th }}, 2021$; Revised: January $30^{\text {st }}$, 2021; Accepted: February $31^{\text {st }}, 2021$

\begin{abstract}
Background: Quality and dose factors are very important in radiodiagnostic examination. To produce a constant radiographic quality, the density and contrast produced must remain constant. There is a rule that aims to produce a constant radiographic quality by adding the exposure value, the $10 \mathrm{kV}$ rule. This study was conducted to determine the noise in the computed radiography image with the thorax organ produced by modifying the exposure factor of the $10 \mathrm{kV}$ rule and whether it is still within tolerance.

Methods: This quantitative research was conducted with an experimental approach. This is done by taking a series of radiographs that include three exposure factor settings, standard $(60 \mathrm{kV}, 10 \mathrm{mAs})$, increased by $10 \mathrm{kV}(70 \mathrm{kV}, 5 \mathrm{mAs})$ and lowered by $10 \mathrm{kV}(50 \mathrm{kV}, 20 \mathrm{mAs})$. Noise measurement is done by doing ROI in the background area. The exposure index and deviation index values were also recorded as quality and dose references. The data was processed and analyzed by statistical tests.

Results: The effect of exposure factor with the $10 \mathrm{kV}$ rule $(70 \mathrm{kV}$ and $50 \mathrm{kV})$ on noise is higher than the standard exposure factor but the difference is not too far, which is 0.2 . The highest exposure index is at 70 $\mathrm{kV}$ and the lowest is at $50 \mathrm{kV}$ where at $50 \mathrm{kV}$ the dose is lower. A good deviation index at $70 \mathrm{kV}$ shows the best radiograph in the $10 \mathrm{kV}$ increment rule. The results of the statistical test of the relationship between $\mathrm{kV}$ and noise showed that at $50 \mathrm{Kv}$ and $20 \mathrm{mAs}, 60 \mathrm{kV}$ and $10 \mathrm{mAs}$ gave a significance value of 0.263 and 0.435 , while at $70 \mathrm{kV}$ and $10 \mathrm{mAs}$ with Sig. (1-tailed) of .000 which means the relationship between $\mathrm{kV}$ to noise is strong because the sig value is below 0.05 .

Conclusions: There is a significant relationship between $\mathrm{kV}$ and noise. From the quality aspect, the most optimum exposure index and deviation index indicators are in the range of $70 \mathrm{KV}$ and $5 \mathrm{mAs}$
\end{abstract}

Keyword: computed radiography images, $10 \mathrm{kV}$ rule, noise

\section{Pendahuluan}

Pemeriksaan radiodiagnostik merupakan pemeriksaan yang memanfaatkan radiasi sinar-X untuk menampakkan obyek yang diinginkan dengan membuat radiograf untuk mendapatkan informasi yang dapat mendukung dalam penegakan diagnosa. Oleh karena itu, diperlukan kualitas radiograf yang optimal untuk menunjang hal tersebut. Pengaturan faktor eksposi yang tepat merupakan salah satu cara untuk menghasilkan kualitas radiograf yang optimal (Bushong, 2001).

Faktor eksposi merupakan faktor yang menentukan intensitas dan kualitas sinar-X yang diterima oleh pasien. Faktor eksposi yang dapat di kontrol yaitu: tegangan tabung $(\mathrm{kVp})$, arus tabung (mAs), waktu penyinaran (second), dan jarak tabung sinar-X ke film (FFD). Selain itu terdapat faktor eksposi yang merupakan kesatuan dari pesawat yaitu generator sinar-X, filter, dan ukuran focal spot (Bushong, 2001).

Tegangan tabung $(\mathrm{kVp})$ mempengaruhi faktor utama yang mengontrol kualitas sinar- $X$ yaitu kemampuan sinar-X untuk menembus obyek yang dilaluinya. Tegangan tabung $(\mathrm{kVp})$ mempengaruhi kontras radiograf yang dihasilkan, hal ini ditandai dengan adanya perbedaan kehitaman antara beberapa daerah pada radiograf (Bushong, 2001).

Arus tabung (mA) merupakan arus yang mengalir pada tabung penyinaran yang menentukan intensitas sinar- $X$ sampai ke film. Menambah nilai arus tabung (mA) akan meningkatkan densitas rata-rata sehingga radiograf akan tampak lebih hitam. Selain itu, peningkatan arus tabung (mA) lebih dari setengahnya dengan waktu eksposi tetap akan menghasilkan 
penambahan dosis yang diterima pasien menjadi dua kali (Bushong.2001).

Waktu penyinaran (second) menentukan lamanya laju penyinaran. Perubahan nilai kuat arus tabung dan waktu penyinaran (mAs) akan menimbulkan pengaruh terhadap besarnya energi berkas sinar-X, total yang dihasilkan oleh tabung sinar-X selama eksposi. Nilai kuat arus tabung dan waktu penyinaran (mAs) atau eksposi akan berpengaruh terhadap kuantitas radiasi, densitas optik, dan dosis pasien (Bushong, 2001).

Focus Film Distances (FFD) menentukan intensitas sinar-X yang sampai ke film dan tidak berpengaruh terhadap kualitas radiasi. FFD mempengaruhi densitas optik pada radiograf. Semakin jauh FFD maka semakin sedikit intensitas sinar- $X$ yang sampai ke film sehingga menghasilkan densitas yang rendah, dan sebaliknya (Bushong, 2001).

Pengaturan faktor eksposi ini dapat menentukan besar kecilnya dosis radiasi yang akan diterima oleh pasien. Salah satu cara untuk menurunkan dosis yang diterima oleh pasien yaitu dengan cara menaikkan tegangan tabung $(\mathrm{kVp})$ dan diikuti dengan penurun nilai kuat arus dan waktu penyinaran (mAs). Pemilihan tegangan tabung $(\mathrm{kVp})$ tinggi dan tetap menjaga kualitas radiograf yang konsisten adalah salah satu cara yang tepat untuk mengurangi dosis. Untuk menghasilkan kualitas radiograf yang konstan, maka densitas dan kontras yang dihasilkan harus tetap konstan. Terdapat suatu aturan yang bertujuan untuk menghasilkan kualitas radiograf yang konstan dengan menambahkan nilai eksposi, yaitu aturan $10 \mathrm{kV}$. Aturan ini menyatakan bahwa untuk menghasilkan nilai densitas yang sama, maka perubahan tegangan tabung $(\mathrm{kVp})$ harus diikuti oleh perubahan nilai kuat arus tabung dan waktu penyiran (mAs). Setiap kenaikan tegangan tabung $(\mathrm{kVp})$ sebasar $10 \mathrm{kV}$ dan penurunan separuh nilai kuat arus tabung dan waktu penyinaran (mAs), maka akan menghasilkan densitas yang sama (Carlton dan Adler, 2001).

Ada beberapa literatur yang juga membahas tentang modifikasi faktor eksposi. Antara lain aturan $10 \mathrm{kv}$ dan aturan $15 \%$. Aturan $10 \mathrm{kV}$ adalah aturan yang menyatakan perubahan $10 \mathrm{kV}$ dari $\mathrm{kV}$ semula disertai dengan penurunan atau penambahan mAs sebesar setengahnya dari $\mathrm{mAs}$ semula. Aturan ini bisa digunakan pada rentang tegangan tabung 50-80 kV (Rasad, 2005). Sedangkan aturan $15 \%$ adalah aturan yang menyatakan bahwa kenaikan $\mathrm{kV}$ sebesar $15 \%$ tegangan tabung dan disertai dengan penurunan setengah mAs maka akan menghasilkan densitas yang konstan. Aturan ini lebih tepat digunakan pada rentang tegangan tabung $60-100 \mathrm{kV}$ (Carlton dkk, 2001).

Kualitas radiograf yaitu kemampuan suatu radiograf dalam memberikan informasi yang optimal dari obyek yang diperiksa. Kualitas radiograf terdiri dari dua aspek, yaitu aspek fotografik dan aspek geometri. Aspek fotografi terdiri dari densitas dan kontras, sedangkan aspek geometris terdiri dari recorded detail dan distorsi. Dengan melakukan modifikasi faktor eksposi juga akan mempengaruhi timbulnya noise pada radiograf. Dimana noise merupakan salah satu faktor yang dapt mempengaruhi kulaitas radiograf.

Di dalam dunia kedokteran pemeriksaan radiologi thorax salah satu pemeriksaan yang sangat penting karena dapat menafsirkan organorgan penting didalamnya seperti paru-paru dan jantung. Pemeriksaan thorax berfungsi untuk mendeteksi berbagai kelainan dini sebelum timbul gejala-gejala klinis. Sehingga pemeriksaan thorax sering dilakukan secara rutin pada orang-orang yang tidak mempunyai keluhan apa-apa. Untuk membantu dalam menegakkan diagnosa, maka hasil radiograf harus memiliki kualitas radiograf yang optimal yang dapat memberikan informasiinformasi diagnostik yang dikehendaki sehingga dapat menegakkan diagnosa suatu penyakit.

Penerapan modifikasi faktor eksposi pada pemeriksaan thorak penting untuk dilakukan analisis lebih lanjut mengenai timbulnya noise pada modifikasi faktor eksposi aturan $10 \mathrm{kV}$. Pada penelitian ini dilakukan untuk mengetahui noise pada citra computed radiography (CR) dengan organ thorax yang dihasilkan pada modifikasi faktor eksposi aturan $10 \mathrm{kV}$ dan apakah masih dalam toleransi.

\section{Metode}

Jenis penelitian eksperimental. Alat yang digunakan adalah Pesawat sinar-X, Phantom chest, Imaging Plate dan Computed Radiography. Data diperoleh dengan eksposi dengan posisi pemeriksaan radiografi thoraks, dengan titik bidik setinggi vertebra thoracal 7 atau pertengahan kedua angulus inferior scapula. Kolimasi sebesar $35 \times 35$ $\mathrm{cm}$. Eksposi dengan menggunakan tegangan tabung $60 \mathrm{kVp}$, dan kuat arus dan waktu penyinaran $10 \mathrm{mAs}$. Citra hasil ekspose. Setelah dilakukan eksposi imaging plate diproses pada image reader. Citra pada display $\mathrm{CR}$ disimpan dalam bentuk soft copy tanpa dilakukan manipulasi. Ulangi langkah tersebut untuk teknik eksposi kedua (70 kVp, 5 mAs) dan eksposi ketiga 
(50 kVp, $20 \mathrm{mAs})$ masing-masing dilakukan 30 eksposi untuk setiap variasi faktor eksposi tersebut. Selanjutnya dilakukan pengukuran nilai noise menggunakan CR dengan melakukan Region of Interest (ROI) pada area background dan pengukuran nilai noise subjektif dengan menggunakan kuisioner pada responden. Setelah didapatkan hasil nilai kontras subjektif dan objektif pada setiap radiograf, kemudian data dilakukan pengolahan dan dianalisa. Penilaian responden meliputi (1) Area yang tereksposi tanpa objek mempunyai tingkat kehitaman, (2) Tingkat kontras area objek yang tereksposi, (3) Tingkat ketajaman area yang tereksposi pada objek, (4) Tingkat kontras antara area jaringan dengan objek tulang, (5) Noise / artefak yang ditampilkan pada radiograf terlihat, (6) Tingkat kehitaman pada area paru, (7) Tingkat kontras gambaran jantung dibandingkan dengan paru, (8) Ketajaman pada gambaran tepi jantung, (9) Tingkat kontras pada costae terhadap area paru, (10) Tingkat ketajaman pada tepi costae.

\section{Hasil Dan Pembahasan}

Pemotretan phantom thorax proyeksi PA faktor eksposi standar sebesar $60 \mathrm{kV}$ dan $10 \mathrm{mAs}$. Kemudian faktor eksposi tersebut dimodifikasi menggunakan aturan $10 \mathrm{kV}$ sehingga didapatkan faktor eksposi dengan aturan $10 \mathrm{kV}$ yaitu: $50 \mathrm{kV}$ dan $20 \mathrm{mAs}, 70 \mathrm{kV}$ dan $5 \mathrm{mAs}$.

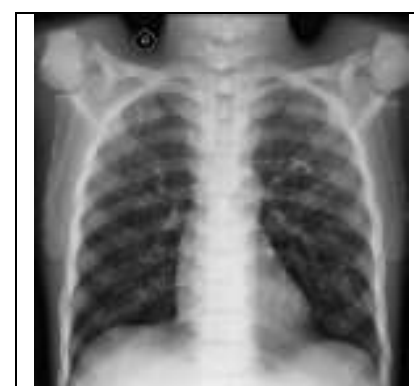

(a)

Gambar 1. Pembuatan Radiograf kV Normal 60 kV dan 10 mAs (a) Radiografi Thorak dan (b) Histogram

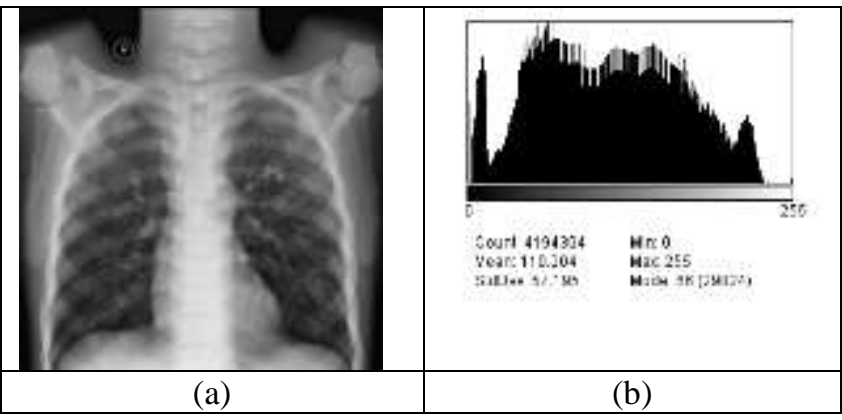

Gambar 2. Pembuatan Radiograf kV naik $70 \mathrm{kV}$ dan 5 mAs (a) Radiografi Thorak dan (b) Histogram

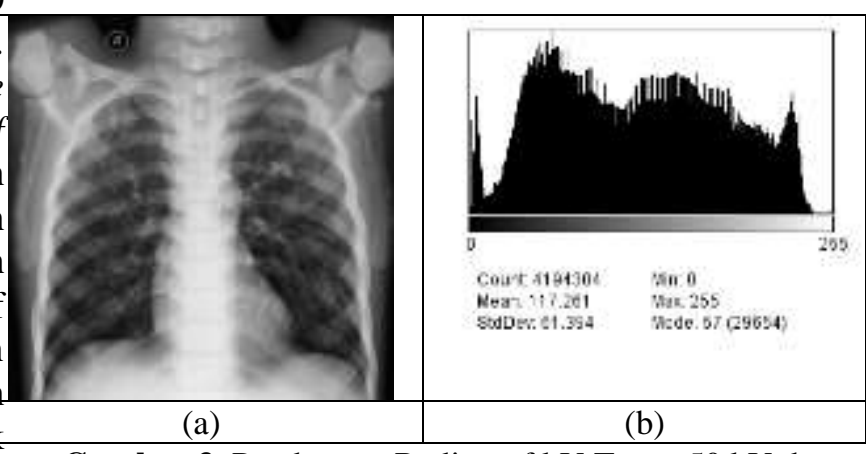

Gambar 3. Pembuatan Radiograf kV Turun $50 \mathrm{kV}$ dan 20 mAs (a) Radiografi Thorak dan (b) Histogram

Gambar 1 s.d 3 menunjukkan radiograf thorax dari phantom dengan proyeksi AP dan histogram yang memperlihatkan kualitas dari gambar tersebut. Dari radiograf thorak dapat dilihat kualitas radiograf yang dibuat dapat memperlihatkan tingkat kehitaman (density), perbedaan kehitaman diantara kedua area yang berdekatan (kontras) dan kemampuan memperlihatkan organ yang sangat kecil (detail) dan hal ini dilihat secara kualitatif berdasarkan subyektifitas seseorang. Pada histogram arah sumbu $\mathrm{x}$ adalah memuat nilai grey scale sebanyak 256 (dari 0 sampai 255) dan arah sumbu y adalah jumlah atau intensitas dari skala yang ada. Rentang kerataan histogram panjang serta intensity yang rata menunjukkan kontras radiograf yang baik.

Dari data diatas dapat diketahui histogram yang di tampilkan nilai gray level pada radiograf standard dengan aturan $10 \mathrm{kV}$ tersebut mengalami kerataan yang sama, tidak mengalami kecondongan nilai gray level ke kiri ataupun ke kanan. Dengan kerataan grafik histogram pada nilai gray level tersebut dapat disimpulkan bahwa perubahan kontras radiograf standard dengan aturan $10 \mathrm{kV}$ tidak mengalami perubahan yang signifikan yang dapat dikatakan bahwa kontras objektif pada radiograf dengan aturan $10 \mathrm{kV}$ konstan atau homogen.

\section{Hasil Pengukuran Noise}

Tabel 1 menunjukkan hasil rata rata noise pada faktor eksposi $60 \mathrm{kV}$ sebesar $3,7 \quad 50 \mathrm{kV}$ sebesar 4,0 dan $70 \mathrm{kV}$ sebesar 4,1 serta EI pada faktor eksposi $60 \mathrm{kV}$ sebesar 1573,47 $50 \mathrm{kV}$ sebesar 1445,07 dan $70 \mathrm{kV}$ sebesar 1607,8 dan Indeks deviasi pada faktor eksposi $60 \mathrm{kV}$ sebesar -0,53 50 $\mathrm{kV}$ sebesar -1,44 dan $70 \mathrm{kV}$ sebesar -0,22

\section{Hasil Penilaian Kuesioner Responden}

Penelitian ini selain dilakukan pengukuran secara kuantitatif juga dilakukan secara kualitatif dengan responden 3 Radiolog yang mempunyai 
karakteristik yang hampir sama. Dari ketiga responden kemudian dilakukan uji Cohen's Kappa. Hasil uji kappa responden 1 dan 2 sebesar 0,374, responden 2 dan 3 adalah $-0,061$ dan responden 2 dan 3 adalah -0,075. Dari hasil uji kappa ketiga responden memenuhi syarat uji kappa yg baik -1 sampai dengan 1 yang artinya ketiga responden mempunyai persepsi yang sama.

Kemudian dengan uji korelasi, didapatkan hasil statistik yang menunjukkan hubungan antara nilai eksposi yang diberikan dengan tingginya noise yang terkandung didalam hasil radiograf atau citra rontgen. Hasil pengujian menghasilkan data sebagai berikut, dengan $50 \mathrm{kV} 20 \mathrm{mAs}$ dan $60 \mathrm{kV}$ 10 mAs tidak menunjukkan adanya hubungan, karena nilai signifikansinya adalah lebih dari 0,05 yaitu 0,263 dan 0,435 . Sedangkan pada nilai eksposi $70 \mathrm{kV} 5 \mathrm{mAs}$ menunjukkan adanya hubungan yang kuat, karena nilai signifikansinya 0,00 (kurang dari 0,05), sebagaimana ditunjukkan pada table 2 . 
Tabel 1. Hasil Pengukuran Noise pada Radiograf

\begin{tabular}{|c|c|c|c|c|c|c|c|c|c|}
\hline \multirow{4}{*}{ NO } & \multicolumn{9}{|c|}{ Faktor Eksposi } \\
\hline & \multicolumn{3}{|c|}{$60 \mathrm{kV} 10 \mathrm{mAs}$} & \multicolumn{3}{|c|}{$50 \mathrm{kV} 20 \mathrm{mAs}$} & \multicolumn{3}{|c|}{$70 \mathrm{kV} 5 \mathrm{mAs}$} \\
\hline & \multicolumn{3}{|c|}{ ROI BACKGROUND } & \multicolumn{3}{|c|}{ ROI BACKGROUND } & \multicolumn{3}{|c|}{ ROI BACKGROUND } \\
\hline & Std & IE & ID & Std & IE & ID & Std & IE & ID \\
\hline 1 & 3,1 & 1571 & $-0,52$ & 3,8 & 1491 & $-1,22$ & 3,6 & 1610 & $-0,11$ \\
\hline 2 & 5,1 & 1578 & $-0,47$ & 3,9 & 1465 & $-1,54$ & 4,6 & 1591 & $-0,31$ \\
\hline 3 & 3,4 & 1559 & $-0,62$ & 4,2 & 1453 & $-1,39$ & 3,3 & 1624 & $-0,08$ \\
\hline 4 & 3,6 & 1569 & $-0,51$ & 3,7 & 1443 & $-1,54$ & 3,9 & 1602 & $-0,32$ \\
\hline 5 & 3,4 & 1560 & $-0,65$ & 4,9 & 1456 & $-1,52$ & 5 & 1620 & $-0,46$ \\
\hline 6 & 4,1 & 1556 & $-0,66$ & 4,3 & 1446 & $-1,43$ & 3,9 & 1598 & $-0,33$ \\
\hline 7 & 5,1 & 1556 & $-0,66$ & 3,4 & 1459 & $-1,46$ & 3,4 & 1617 & $-0,09$ \\
\hline 8 & 5,2 & 1558 & $-0,63$ & 3,9 & 1446 & $-1,44$ & 4,5 & 1605 & $-0,23$ \\
\hline 9 & 3,1 & 1550 & $-0,71$ & 4,6 & 1458 & $-1,38$ & 4,4 & 1617 & $-0,09$ \\
\hline 10 & 3,9 & 1572 & $-0,47$ & 4,1 & 1447 & 1,48 & 4,6 & 1606 & $-0,22$ \\
\hline 11 & 5,3 & 1560 & $-0,61$ & 4,5 & 1456 & $-1,46$ & 5,2 & 1615 & $-0,12$ \\
\hline 12 & 3,9 & 1565 & $-0,56$ & 4 & 1443 & $-1,53$ & 2,8 & 1609 & $-0,2$ \\
\hline 13 & 4,3 & 1556 & $-0,62$ & 4,5 & 1451 & $-1,51$ & 4,1 & 1613 & $-0,13$ \\
\hline 14 & 3,1 & 1572 & $-0,47$ & 4,6 & 1441 & $-1,51$ & 4,7 & 1606 & $-0,22$ \\
\hline 15 & 3,7 & 1554 & $-0,67$ & 3,8 & 1452 & $-1,54$ & 3,4 & 1615 & $-0,13$ \\
\hline 16 & 2,5 & 1589 & $-0,45$ & 3,6 & 1440 & $-1,59$ & 4,4 & 1604 & $-0,24$ \\
\hline 17 & 3,3 & 1594 & $-0,42$ & 5,6 & 1444 & $-1,47$ & 4,1 & 1615 & $-0,13$ \\
\hline 18 & 4,2 & 1581 & $-0,5$ & 3,5 & 1429 & $-1,65$ & 3,3 & 1603 & $-0,26$ \\
\hline 19 & 3,2 & 1595 & $-0,36$ & 3,6 & 1446 & $-1,61$ & 4,5 & 1605 & $-0,24$ \\
\hline 20 & 5,3 & 1579 & $-0,52$ & 4 & 1434 & $-1,63$ & 3,6 & 1606 & $-0,23$ \\
\hline 21 & 3,0 & 1590 & $-0,42$ & 4,9 & 1444 & $-1,62$ & 3,8 & 1612 & $-0,16$ \\
\hline 22 & 5,0 & 1576 & $-0,53$ & 3,6 & 1437 & $-1,63$ & 3,8 & 1605 & $-0,23$ \\
\hline \multirow{4}{*}{ NO } & \multicolumn{9}{|c|}{ Faktor Eksposi } \\
\hline & \multicolumn{3}{|c|}{$60 \mathrm{kV} 10 \mathrm{mAs}$} & \multicolumn{3}{|c|}{$50 \mathrm{kV} 20 \mathrm{mAs}$} & \multicolumn{3}{|c|}{$70 \mathrm{kV} 5 \mathrm{mAs}$} \\
\hline & \multicolumn{3}{|c|}{ ROI BACKGROUND } & \multicolumn{3}{|c|}{ ROI BACKGROUND } & \multicolumn{3}{|c|}{ ROI BACKGROUND } \\
\hline & Std & IE & ID & Std & IE & ID & Std & IE & ID \\
\hline 23 & 2,4 & 1588 & $-0,44$ & 4,1 & 1437 & $-1,53$ & 2,8 & 1614 & $-0,15$ \\
\hline 24 & 4,6 & 1578 & $-0,53$ & 3,7 & 1421 & $-1,73$ & 4,1 & 1601 & $-0,28$ \\
\hline 25 & 3,6 & 1589 & $-0,43$ & 3,8 & 1435 & $-1,63$ & 4,8 & 1615 & $-0,13$ \\
\hline 26 & 3,3 & 1578 & $-0,53$ & 3,8 & 1429 & $-1,63$ & 5,4 & 1603 & $-0,26$ \\
\hline 27 & 3,2 & 1589 & $-0,44$ & 2,9 & 1439 & $-1,54$ & 3,8 & 1608 & $-0,2$ \\
\hline 28 & 2,7 & 1578 & $-0,54$ & 4,2 & 1429 & $-1,68$ & 5,4 & 1603 & $-0,25$ \\
\hline 29 & 2,4 & 1586 & $-0,47$ & 4,4 & 1445 & $-1,63$ & 3,3 & 1598 & $-0,32$ \\
\hline 30 & 2,7 & 1578 & $-0,54$ & 3,3 & 1436 & $-1,59$ & 4,3 & 1594 & $-0,35$ \\
\hline $\begin{array}{l}\text { Rata- } \\
\text { rata }\end{array}$ & 3,7 & 1573,47 & $-0,53$ & 4,0 & 1445,07 & $-1,44$ & 4,1 & 1607,8 & $-0,22$ \\
\hline
\end{tabular}

Tabel 2. Hasil uji statistik hubungan antara Faktor eksposi terhadap Noise

\begin{tabular}{cccc}
\hline Signifikansi & $\begin{array}{c}\text { Noise pada } \\
\text { citra } 50 \mathrm{kV}\end{array}$ & $\begin{array}{l}\text { Noise pada } \\
\text { citra } 60 \mathrm{kV}\end{array}$ & $\begin{array}{c}\text { Noise pada } \\
\text { citra70 kV }\end{array}$ \\
\hline $50 \mathrm{kV}, 20 \mathrm{mAs}$ & 0,263 & & \\
$60 \mathrm{kV}, 10 \mathrm{mAs}$ & & 0,435 & 0,00 \\
\hline $70 \mathrm{kV}, 5 \mathrm{mAs}$ & & & 0.000 \\
\hline
\end{tabular}

Pada modifikasi faktor eksposi dari hasil pengukuran dengan melakukan ROI di luar obyek yang difoto diperoleh nilai noise yang tidak jauh berbeda yaitu 3,7; 4,0 dan 4,1, Nilai noise pada aturan $10 \mathrm{kV}$ lebih tinggi di banding faktor Eksposi Standar. Noise tertinggi di $70 \mathrm{kv}$ sebesar 4,07, 50 $\mathrm{kV}$ sebesar 4,04 dan $60 \mathrm{kV}$ sebesar 3,7 perbedaan 
tidak cukup signifikan perbedaan diantara faktor eksposi standar sebesar 0,2. Pengunan modifikasi faktor eksposi memberikan noise yang besar karena pada kenaikan tegangan dan penambahan mAs akan meningkatkan noise dimana noise dipengaruhi oleh banyak faktor yaitu $\mathrm{kV}, \mathrm{mAs}$, filtrasi, dan kolimator (Seibert, 2006). Menurut Meredith dan Massey (1997) menyatakan bahwa peningkatan tegangan tabung akan meningkatkan daya tembus sinar- $X$, sehingga sinar- $X$ menimbulkan kehitaman pada film juga semakin banyak.

Nilai indek deviasi faktor eksposi $60 \mathrm{kV}$ sebesar -0,53 $50 \mathrm{kV}$ sebesar $-1,44$ dan $70 \mathrm{kV}$ sebesar $-0,22$. Dimana pada nilai $-0,5$ sampai 0,5 menunjukkan radiograf yang baik dan ditunjukkan pada $\mathrm{kV}$ yang naik $10 \mathrm{kV}$ dan turun $\mathrm{mAs}$ setengahnya yaitu pada aturan $10 \mathrm{kV}$. Eksposure Indek dari ketiga gambar antar faktor ekspsi standar dan aturan $10 \mathrm{kV}$ pada faktor eksposi 60 $\mathrm{kV}$ sebesar 1573,47 $50 \mathrm{kV}$ sebesar 1445,07 dan 70 $\mathrm{kV}$ sebesar 1607,8 dimana nilai tersebut masih dalam rentang nilai yang direkomendasikan oleh Carestream yaitu 1300 sampai dengan 1800 . Ekposure Indek (EI) selain untuk menentukan image quality juga dapat untuk memperkirakan dosis yang diterima pasien yaitu dengan melihan EI yg kecil dosis lebih kecil. Ekposure indek urutan dari paling under exposere sampai besar di $50 \mathrm{kV}, 60 \mathrm{kV}, 70 \mathrm{kV}$ artinya ekposure yg diberikan pda $50 \mathrm{kV}$ paling rendah diantara yang lain berarti dosis lebih rendah ditunjukkan pada $50 \mathrm{kV}$ yaitu pengunaan aturan $10 \mathrm{kV}$ yaitu turun $10 \mathrm{kV}$ dan mAs dua kalinya. Dosis pasien ditentukan oleh faktor teknis sinar $\mathrm{X}(\mathrm{kV}, \mathrm{mAs}$, grid, SID, filtrasi, kolimasi berkas), penetrasi dan kualitas berkas sinar-X, sejumlah energi yang sampai ke organ tubuh, dan ukuran atau luas obyek yang terkena radiasi.

Berdasarkan uji statitistik pengaruh $\mathrm{kV}$ terhadap noise diperoleh hasil pada $50 \mathrm{Kv}$ dan 20 mAs, $60 \mathrm{kV}$ dan $10 \mathrm{mAs}$, tidak ada hubungan antara perubahan nilai eksposi dan timbulnya noise (nilai signifikansi 0,263 dan 0,435). Sedangkan pada $70 \mathrm{kV}$ dan $10 \mathrm{mAs}$ memberikan nilai signifikansi sebesar ,000 yang berarti hubungan $\mathrm{kV}$ terhadap noise kuat karena nilai signifikan dibawah 0,05 .

\section{Simpulan}

Dari penelitian ini didapatkan simpulan pengaruh faktor eksposi dengan aturan $10 \mathrm{kV}$ (70 $\mathrm{kV}$ dan $50 \mathrm{kV}$ ) terhadap noise lebih tinggi bila dibandingkan faktor eksposi standar namun perbedaan tidak terlalu jauh yaitu sebesar 0,2. Ekposure Indeks tertinggi pada $70 \mathrm{kV}$ dan terendah pada $50 \mathrm{kV}$ dimana pada $50 \mathrm{kV}$ dosis lebih rendah. Indeks deviasi yang baik pada $70 \mathrm{kV}$ hal ini menunjukkan radiograf terbaik pada aturan kenaikan $\mathrm{kV}$ 10. Hasil uji statitistik hubungan $\mathrm{kV}$ terhadap Noise diperoleh hasil pada $50 \mathrm{Kv}$ dan 20 mAs, $60 \mathrm{kV}$ dan $10 \mathrm{mAs}$ memberikan nilai signifikansi sebesar 0,263 dan 0,435 , sedangkan pada $70 \mathrm{kV}$ dan $10 \mathrm{mAs}$ dengan Sig. (1-tailed) sebesar ,000 yang berarti hubungan antara $\mathrm{kV}$ terhadap noise kuat karena nilai sig dibawah 0,05.

\section{Daftar Pustaka}

Arymurthy, A DKK, Pengantar Pengolahan Citra, PT Elex Media Komputindo Kelompok Gramedia, Jakarta1992

Ballinger, Philip W, Merril of Atlas Radiographic Positioning and Radiologic Procedure, Eight Edition Vol. III. Missouri, Mosby, Inc., 2003

Bushong, SC, Radiologic Science For Technologist Physic, Biology and Protection, Seventh Edition, The CV Mosby Company, Washington DC, 2001

Carlton, Richard R. and Adler M. Arlene, Principle Radiographic Imaging An Art And Science, JRD Edition, Mosby Company, Toronto, 2001

Mervyn D. Cohen, Matt L. Cooper, Kelly Piersal, Bruce K. Apgar, Quality assurance : using the exposure index and the deviation index to monitor radiation exposure for postable chest radiograps in neonates, Pediatric Radiology DOI 10.1007/s00247-010-19519. (C) Springer-Verlag, 2010

J.A. Seibert, Richard L. Morin, The standardized exposure index for digital radiography : an opportunity for optimization of radiation dose to the pediatric population. Pediatric Radiology 41:573-581. (C) Springerlink.com, 2011

Papp, Jeffrey, Quality Management In The Imaging Science, Third Edition. Mosby Inc, United States Of America, 2006

Pujiati, Pengaruh Kenaikan $k V$ aturan $15 \%$ Terhadap Kualitas Radiograf dan Paparan Radiasi, DIII Teknik Radiodiagnostik Dan Radioterapi Semarang: Politeknik Kesehatan Kementrian Kesehatan Semarang, 2006

Rasad, S Dkk, Radiologi Diagnostik, Gaya Baru: Jakarta, 2005 
Seibert, dkk, Acceptance Testing And Quality Control of Photostimulable Storage Phospor Imaging System, www.aapm.org. Diakses pada tanggal 2 Februari 2016, 2006

Utomo, Pengaruh Modifikasi Faktor Eksposi dengan Metode Aturan $10 \mathrm{kV}$ Terhadap
Kualitas Radiograf (Densitas dan Kontras) Pada Radiograf Ankle Joint, DIII Teknik Radiodiagnostik Dan Radioterapi Semarang: Politeknik Kesehatan Kementrian Kesehatan Semarang, 2006 